\title{
MAPAS DE UM ESPAÇO-TEMPO: UMA CARTOGRAFIA DO TERRITÓRIO ESCOLAR NA SOCIEDADE DE CONTROLE
}

\author{
Mirele Corrêa ${ }^{1}$
}

Gicele Maria Cervi ${ }^{2}$

\section{Há muitas entradas num mapa...}
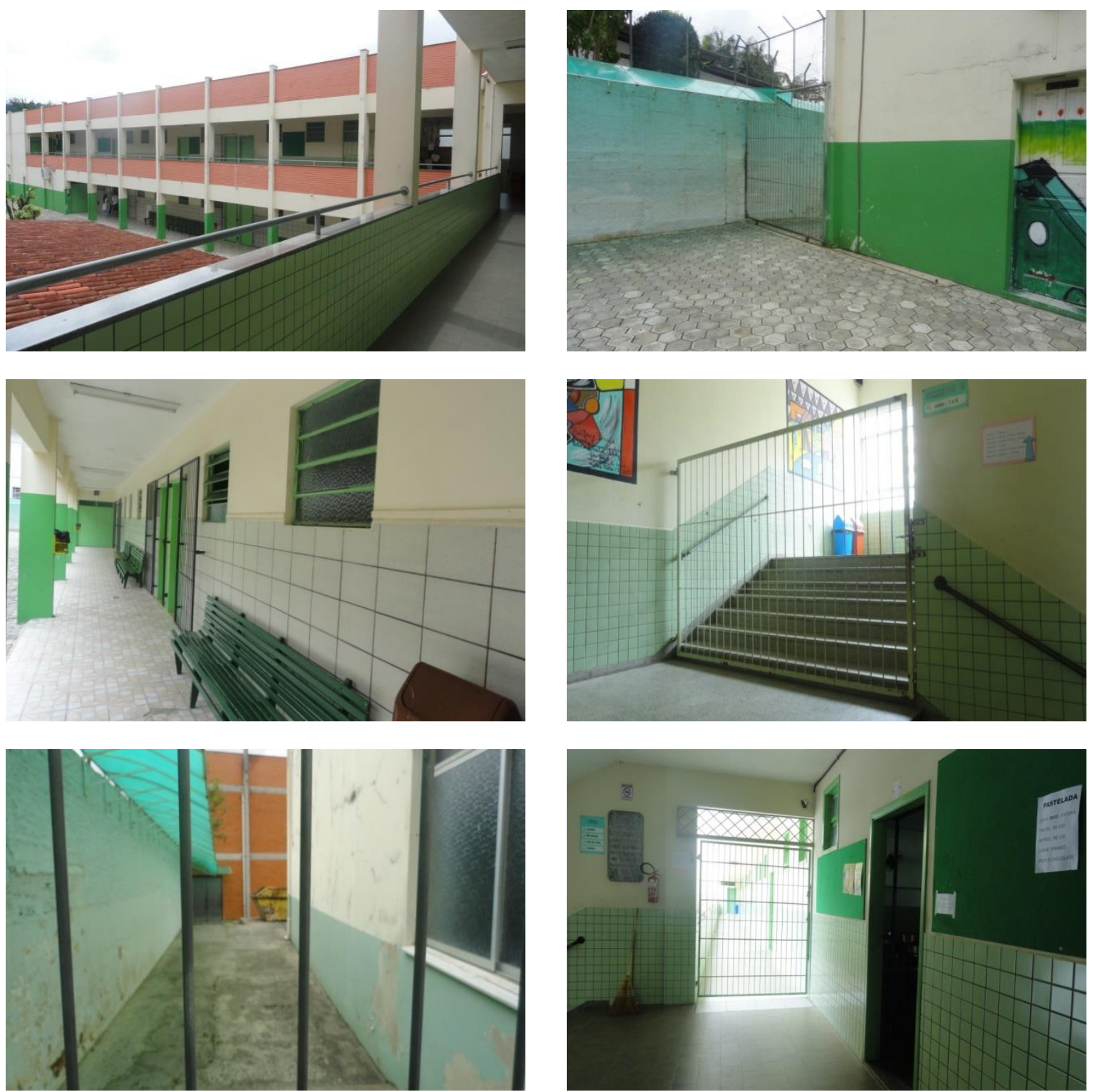

Fonte: Imagens sacadas pela pesquisadora Mirele Corrêa.

\footnotetext{
${ }^{1}$ Pedagoga (2012) e Mestre em Educação (2017) pela Universidade Regional de Blumenau - FURB. E-mail: mirele_correa@yahoo.com.br.

${ }^{2}$ Professora e Coordenadora do PPGE-ME da Universidade Regional de Blumenau - FURB. Coordenadora do Grupo de Pesquisa Políticas de Educação na Contemporaneidade.E-mail: gicelel.cervi@gmail.com.
} 


\title{
... O que é preciso saber para mo(ver)-se
}

\author{
Deixa o espaço revelar a condição \\ E as palavras menos tortas fundirem os pensamentos \\ Difundirem claras nossas sombras, \\ nossas silhuetas desmontadas no todo \\ Sem começo nem fim previsível \\ De lirismo (s)em verdade
}

[Claudia Iara Vetter, 2011]

A escola está em cada um de nós. Ela nos habita, porque nós a habitamos ao longo de muitos anos. As marcas da escolarização são vividas e sentidas em nosso corpo. Todavia ao adentrar este espaço enquanto pesquisadora ${ }^{3}$ a sensação do que ora nos foi familiar se perde, ganha outras dimensões e o estranhamento sobrepuja. É das Unheimliche ${ }^{4}$ freudiana que nos suscita uma sensação de angústia e confusão àquilo que é desde a muito conhecido. É o estado de estrangeiro em sua própria terra que com um olhar mais cauteloso, atencioso e preciso começa a perceber coisas que antes a ele eram banais. $\mathrm{O}$ estrangeiro imerso nesse movimento deixa o espaço revelar as condições e pousa sua atenção aos detalhes sem projetar um começo nem fim previsível. Ele adentra pelo meio e incorpora a postura agrimensora-que se perde, que procura, que não imerge na burocracia do Castelo, que não mede (regiamente), mas apalpa (nomadologicamente) o território em seus caminhos e descaminhos -, o desconhecido nos toma e o estranhamento é inevitável, o agrimensor, como se o disse, nômade, é capaz de estranhar, pois é sempre estrangeiro ao que agrimensura.

Tudo atrai seu olhar, as direções são múltiplas, chamam atenção, desafia o entendimento, causa certa vertigem, aflição. As imagens trazidas na abertura da introdução buscam de alguma maneira dar língua a expressões que pedem passagem. Essa composição de imagens é um mapa de intensidades, que não necessitam de legendas ${ }^{5}$, porque comunicam por si só, falam com o leitor, mobilizam para um diálogo que transita entre teóricos e poetas, poemas... convida a uma entrada no mapa.

Mas para mo(ver)-se nesse mapa se faz necessário algumas coordenadas, não com a intenção de ordenar ou de conduzir, mas de ir com. Dando pistas, indicando alguns caminhos e possibilidades. Assim, este artigo $^{6}$ se faz, objetivando discutir o território escolar na atual sociedade de controle anunciada por Deleuze $(2013)^{7}$. Território de disputas, repleto de

\footnotetext{
${ }^{3}$ Sobre a utilização das pessoas gramaticais no artigo, seguimos o mesmo fluxo que Deleuze e Guattari (2011, p. 17), "Escrevemos o Anti-Édipo a dois. Como cada um de nós era vários, já era muita gente. [...] Não chegar ao ponto em que não se diz mais EU, mas ao ponto em que já não tem qualquer importância dizer ou não dizer EU. Não somos mais nós mesmos. [...] Cada um é vários, cada um já é um “nós".

${ }^{4}$ Conferir o conceito de estranho-familiar em "O Inquietante” (FREUD, 1919).

${ }^{5}$ Conferir "Mapas, prisões e fugas: cartografias intensivas em educação" (PREVE, 2010), em que os mapas não precisam de legenda, mas precisam do processo para serem lidos.

${ }^{6}$ Recorte de uma pesquisa maior de mestrado que buscou cartografar as potencialidades do corpo em espaço de escolarização. Conferir Corrêa, 2017.

${ }^{7}$ Deleuze (2013, p. 220, grifos do original) afirma que "é certo que entramos em sociedades de 'controle', que já não são exatamente disciplinares. Foucault é com frequência considerado como o pensador das sociedades de disciplina, e de sua técnica principal, o confinamento (não só o hospital, e a prisão, mas a escola, a fábrica, a caserna). Porém, de fato, ele é um dos primeiros a dizer que as sociedades disciplinares são aquilo que estamos deixando para trás, o que já não somos. Estamos entrando nas sociedades de controle, que funcionam não mais por confinamento, mas por controle contínuo e comunicação instantânea”. As sociedades não somem ou se anulam, elas vão antes transitando de forma a reatualizar seus dispositivos de controle e regulação.
} 
ambiguidades e inquietações. Por meio de uma cartografia realizada numa escola pública estadual do município de Blumenau-SC, no ano de 2016, o artigo cartografa, mapeia, habita territórios, problematiza as vivências e as falas de professores e estudantes que fazem parte de um currículo ${ }^{8}$ específico conhecido como Ensino Médio Inovador. Durante quatorze dias foram realizadas observações em uma turma de $3^{\circ}$ ano do Ensino Médio, composta de 8 estudantes. Estas observações compuseram um diário de campo que também relata as vivências em uma oficina cinematográfica realizada com os estudantes.

Tomamos a cartografia como uma forma de se fazer pesquisa, que não exige um método pré-determinado, mas que experimenta um exercício do pensamento, a exemplo do que propôs Deleuze e Guattari. Conforme Passos, Kastrup e Escóssia (2009, p. 10) a cartografia propõe uma reversão metodológica, "um método não para ser aplicado, mas para ser experimentado e assumido como atitude". A cartografia é esse processo de desenhar mapas, de traçar as linhas, de fazer conexões que vão se encontrando, se construindo, se reinventando, territórios outros que vão se edificando. Ela tem o potencial de acompanhar o objeto durante o processo de pesquisa desemaranhando as linhas de um dispositivo, desmontando-as, rachando-as, na tentativa de saber o que ali, por meio de uma determinação, se está produzindo. A cartografia permite o movimento.

Com a transição da sociedade disciplinar (FOUCAULT, 2010) à sociedade de controle, compreende-se que às práticas disciplinares foram incorporadas outras tecnologias de controle que possibilitam à escola na contemporaneidade estar em sintonia com as exigências da economia neoliberal, operando na produção de outros corpos para este tempo. Como afirma Foucault (2010), o corpo pode ser transformado e aperfeiçoado. A cartografia realizada possibilitou compreender os movimentos de um currículo específico que tem uma potencialidade bastante grande para despotencializar o corpo criativo e colocá-lo num fluxo de uma sociedade que busca um corpo cada vez mais performático, produtivo, ocupado, ao mesmo que participativo e vigilante. Vigia de si, polícia dos outros (CERVI, 2013). Uma sociedade que opera constantemente na regulação dos corpos... um corpo (con)formado a uma lógica de controle.

Para mo(ver)-se a escrita opera por fluxos do pensamento que se desdobra em outros, com outros. Escrita que vai traçando mapas de um espaço que "se reinventa a cada dia e que muda aqui e acolá" (ROLNIK, 2014, p. 22), ganhando espessura conforme os afetos e as intensidades de seu tempo. Mapas que se revelam pelas linhas escritas, mas também, pelos desenhos que experimenta ${ }^{9}$. Escrita de mapas de um espaço-tempo. Escrita-mapa que parte de alguns questionamentos: escola, que espaço é este? O que se produz nesse tempo? Problemáticas estas que serão dialogadas nos dois capítulos seguintes junto a alguns teóricos pós-críticos e outros documentos legais que norteiam a política curricular da instituição escolar pesquisada. Vivências e análises são trazidas emaranhadas numa tessitura textual dialógica, onde a metodologia se faz entendida no processo da descrição destas mesmas vivências. Procuraremos no fluxo da escrita contextualizar a escola desde sua invenção às modulações dos tempos atuais.

\footnotetext{
${ }^{8}$ Currículo entendido conforme as teorias pós-críticas é também uma questão de poder e que esse poder está imbricado na produção das teorias, nas tentativas destas em determinar o que o currículo é ou deve ser. Estas teorias enxergam o currículo como uma construção social, um território político, onde o conhecimento não é exterior ao poder e sim parte inerente a ele. As teorias pós-críticas rejeitam a noção de verdade e consciência e desconfiam dos conceitos de alienação, emancipação, libertação, autonomia. Cf. SILVA, 2013.

${ }^{9}$ Ao final do seguinte capítulo será apresentado um mapa, que fora desenhado como estratégia de fazer passar intensidades ligadas a constituição do espaço escolar durante a transição das sociedades disciplinar e de controle.
} 


\section{Mapas do espaço-tempo: da invenção da instituição escolar}

A escola moderna, instituição inventada pela burguesia, que vai se estruturando no decorrer dos séculos XVII, XVIII e XIX, seguia moldes de uma educação disciplinar não apenas passiva, mas ativamente de forma a adestrar corpos e mentes para o novo sistema econômico que se instalava. $\mathrm{O}$ corpo necessário para aquela época era o dócil politicamente e útil economicamente. Além de constituir o sujeito-fábrica, o homem-máquina, por meio de dispositivos disciplinares, na escola passa a atuar, também, dispositivos de controle e regulação desses corpos, pois com o advento das ideias Iluministas, a escola passa a ser responsabilidade do Estado, e este assume um governo condutor sobre as massas - papel antes exercido pela Igreja ${ }^{10}$.

Esse governo condutor estatal procurou acima de tudo, conduzir as conduções, como explicam Caruso e Dussel (2003). Para que ele pudesse se efetivar foi preciso tornar a educação obrigatória e fazê-la relevante. A escola passou a ser o caminho que daria liberdade e autonomia ao indivíduo, fazendo-o pensar que poderia conduzir-se sozinho, sentindo a sensação de liberdade, ao mesmo que estariam sob controle.

O governo não é só para uma pessoa, mas para uma população. Nesse viés, é sobretudo por meio da escola que se vai reforçar um estado de governamentalidade, que permite que sejamos governados. O espaço escolar é uma maquinaria tão bem articulada como dizem Varela e Alvarez-Uria (1992), que consegue governar a massa, diferente do enclausuramento que atuava sobre o corpo específico, individual. A norma, a fragmentação do saber, a massificação do ensino, a seriação, a estrutura panóptica de controle e vigilância, dispositivos que atuam de forma tênue e habitual, com a intencionalidade de produzir um comportamento de auto-condução quase inato.

No interior do estabelecimento educativo tudo se deveria passar como se sobre uma qualquer excitação habitual pudesse aos poucos ir crescendo um movimento voluntário do interior, como se a mecanização de processos transformasse uma atenção involuntária numa atenção livremente desejada pelo aluno. [As] faculdades da alma e a própria liberdade da criança seriam desenvolvidas pelo instrumento mais poderoso que a educação tinha a seu dispor: o hábito. [Buisson] e os demais afirmavam que a regularidade, a repetição e a disciplina, em horários devidamente escalonados em ciclos semanais, acabariam por configurar, com o desenrolar do tempo, um quadro de existência (RAMOS DO Ó, 2003, p. 123, grifo do original).

Ao permanecer quieto, ficar sentado, ao copiar do quadro, formar filas, ao levantar o dedo, fazer provas, entregar trabalhos, escrever o que o outro quer, repetir, reproduzir, responder, todos os dias, cotidianamente, constituímos pela escola um corpo disciplinado passível de ser governado. Conforme Foucault (2010), as disciplinas são técnicas para assegurar a ordenação das multiplicidades humanas e garantir um território seguro ao Estado ${ }^{11}$. Ademais, o hábito que é consequência de atividades repetitivas, produz uma mente incapaz de pensar para

\footnotetext{
${ }^{10}$ A Igreja cristã desempenhou um papel marcante na arte do conduzir os indivíduos e a coletividade por meio do poder pastoral. Poder este, segundo Foucault, que se configurou na arte de todas as artes, no saber de todos os saberes pelos quais as pessoas se deixam governar por alguém. A pastoral se organizou em torno de quatro fundamentos, na qual o pastor tem por responsabilidade conduzir suas ovelhas e zelar por cada uma delas, são estes: a responsabilidade, a obediência e submissão, a forma de conhecimento e a renúncia do mundo e de si mesmo. Cf. FOUCAULT, 2008.

${ }^{11}$ Sobre isso Cf. FOUCAULT, 2008.
} 
além da representação ${ }^{12}$. Um sujeito que aprendeu a vida toda a copiar textos do quadro, dificilmente conseguirá escrever seu próprio texto. Uma pessoa cujos desenhos que pintava durante a infância eram cópias estereotipadas, muito provavelmente não conseguirá produzir suas próprias obras de arte. Quando se ensina uma criança que ela deve permanecer quatro horas sentada numa cadeira, custosamente ela conseguirá realizar uma atividade sentada no chão. A representação se pauta num modelo, num padrão, e força o pensamento no sentido de chegar sempre a uma mesma forma, a um padrão. Carvalho e Gallo (2010) argumentam que a representação é uma máquina binária, que

[opera] no fluxo do significado-significante, angariando padrões, deslocando os pensamentos, as ações, os desejos, as condutas, por intermédio de finalizações e de sentidos que são avalizados pela reprodução do Mesmo. A representação pauta-se pela intensificação da experiência qualitativa; aprofunda-se em um sentido proposto a partir de uma força que se impõe e que também se verticalizará; dá as costas para quantidades de experiências que ameacem quebrar o seu aprofundamento linear na relação do que está representado. Não sem sentido, toda representação generaliza-se no hábito (CARVALHO, GALLO, 2010, p. 284).

A escola se pauta na representação, pois esta é a forma com que ela consegue medir seus resultados e avaliar suas práticas. Ela conduz o pensamento. Parte de um ponto determinado "x" para chegar num ponto " $y$ " e tudo que foge, que escapa ou percorre outro caminho dessa linha que é dura e imparcial, já não corresponde ao que ela espera. Assim, todo desvio é tido como transgressor, pois opera em outra lógica que resiste ao controle da mesma, que escapa a sua condução, fugindo da norma. Contudo, esse binarismo entre representação-criação ou podemos tomar o conceito a exemplo de Deleuze (2006), representação-diferença ${ }^{13}$, não são linhas opostas, contraposições, divergências, são linhas antes paralelas, convergentes, que seguem na mesma direção, estão num mesmo plano e que tem um potencial de transição. É possível transitar, cambiar de uma linha a outra. Essas linhas são dispositivos que operam na escola, por mais que a escola se paute ou transite numa linha representativa, de segmentaridade, as linhas paralelas da diferença estão lá.

A escola dentro da lógica da representação - oriunda de uma sociedade disciplinar (FOUCAULT, 2010) - vai cumprindo sua função. Desde 1918 com a publicação do livro The Curriculum $^{14}$, escrito por Bobbit, os objetivos do mesmo consistiam em conduzir o corpo em que fosse possível medir os resultados, tal qual a produtividade fabril. Este currículo emergiu das teorias administrativas para pensar numa organização que abarcasse as massas (SILVA,

\footnotetext{
${ }^{12}$ A representação aqui é tomada no sentido deleuziano, onde esta se apoia no reconhecimento ou num princípio de identidade. Reconhecer nada tem a ver com pensar, representar é antes uma função recognitiva. Conforme Schöpke, (2012, p. 39, grifo do original) “o termo 'representação' é um vocábulo de origem medieval que indica a imagem ou a ideia (ou ambas as coisas) de um objeto de conhecimento qualquer. Num certo sentido, representar é por sob os olhos alguma coisa, mas é também, tornar presente ao espírito algo que já esteve presente aos nossos sentidos". Cf. DELEUZE, 2000.

${ }^{13}$ A questão da diferença é o ponto central da filosofia deleuziana. Toda sua obra é direcionada na tentativa de romper com a representação clássica do pensamento, pois só por meio dessa ruptura o pensamento é liberado de sua função recognitiva e potencializado de maneira criadora. A diferença condiz com a singularidade do ser e não pode ser estabelecida quando obedece critérios representativos. Sobre o conceito Cf. DELEUZE, 2000 e SCHÖPKE, 2012.

${ }^{14}$ Conforme Silva (2013, p. 22) "o livro de Bobbitt é escrito num momento crucial da história da educação estadunidense, num momento em que diferentes forças econômicas, políticas e culturais procuravam moldar os objetivos e as formas da educação de massas de acordo com suas diferentes e particulares visões", buscando encontrar a finalidade da educação.
} 
2013). Não por acaso, curriculum em latim significa "pista de corrida" e, para percorrer essa pista é preciso de uma condução, condução que leva a um saber, saber que produz efeitos de verdade: ao selecionar uns saberes, excluem-se outros, ao definir um conhecimento como mais importante, define-se um tipo de pessoa ideal e/ou desejável para a sociedade. "Afinal, um currículo busca precisamente modificar as pessoas que vão 'seguir' aquele currículo" (SILVA, 2013, p. 15). O currículo está imbricado de relações de poder-saber que produzem afecções nos corpos dos que ali habitam. Estas afecções, por conseguinte, são responsáveis em determinar as potências de ser e agir desses corpos.

Com a transição da sociedade disciplinar à sociedade de controle o currículo escolar foi cada vez mais se atualizando, reformulando, aprimorando suas ferramentas de controle e regulação. Alguns especialistas tendem a denunciar uma crise escolar na contemporaneidade, entrementes, essa instituição nunca esteve tão bem ancorada, alicerçada e articulada ao sistema econômico neoliberal, produzindo o que dela exige a sociedade. A escola, conforme Cervi (2013, p. 46),

[está] planejada para produzir necessidades e sujeitos necessitados a fim de justificar sua existência, permanência, ampliação e reforma. A escola no século XXI continua reeducando e produzindo os "homens utilizáveis". Ensina muito! Inclui todos ou quase todos! Acentua a diferença! Produz violência! Anestesia! Normaliza! Apazigua! Conserva! Monitora! Trata! Uma maquinaria, um grande negócio.

Seguindo o fluxo das linhas que vão traçando e atravessando o mapa, nos propomos no capítulo seguinte dar visibilidade a escola pesquisada, percebê-la em seus movimentos, compassos e descompassos, pois o mundo se percebe, como afirma Skliar (2014), não se conceitua. A intencionalidade é dar língua aos afetos que foram cartografados, deixar passar as expressões do cotidiano escolar que atravessam os sujeitos desse território e mostrar a partir desse mapeamento como a escola vai se (con)formando a uma lógica político-econômica. Antes, porém, tencionamos as linhas ligando-as a um mapa artístico-poético-político dessa reatualização da sociedade. 


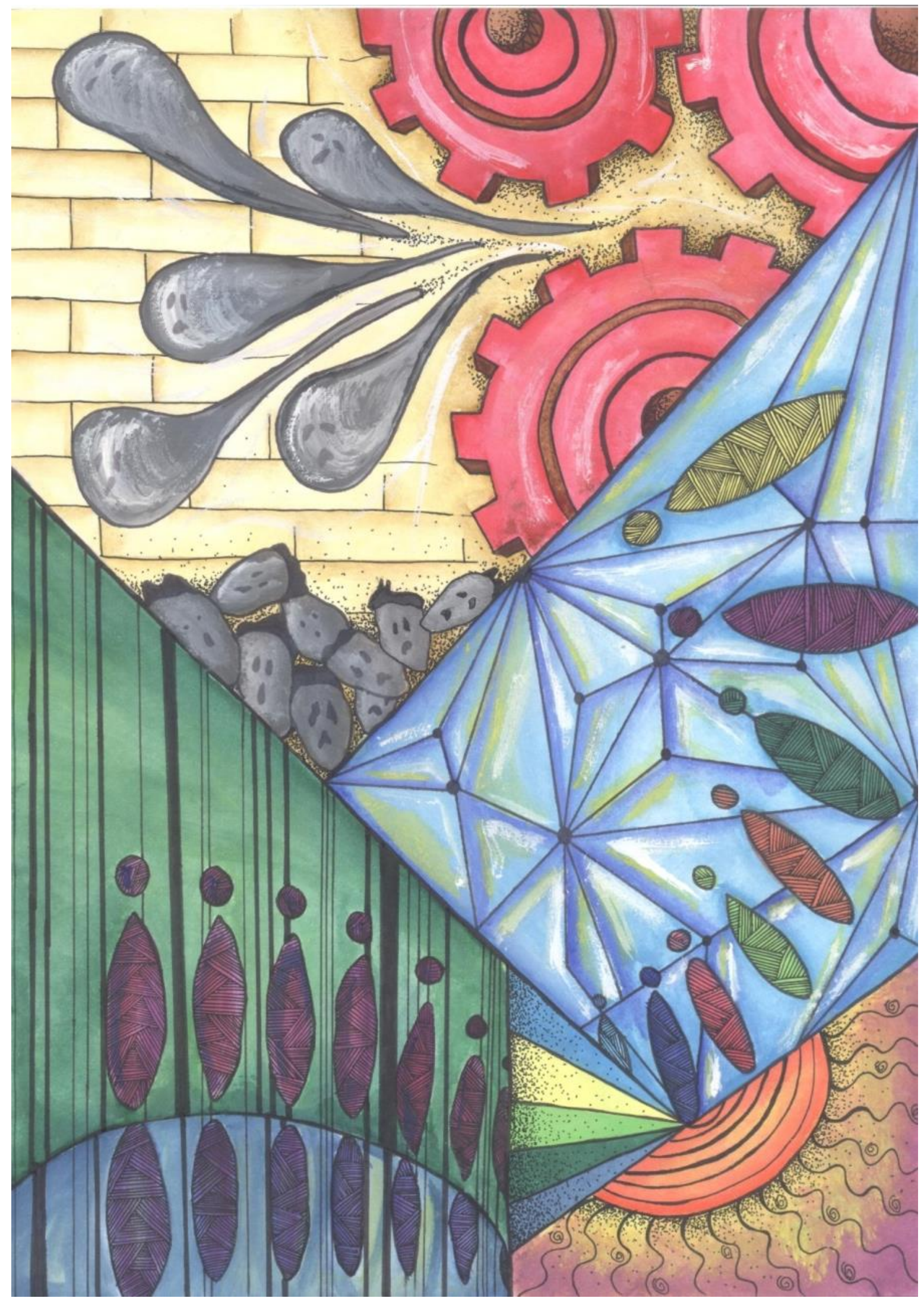

FONTE: Obra desenvolvida pela pesquisadora Mirele Corrêa. 


\section{Mapas do espaço-tempo: da instituição escolar pesquisada}

A escola-campo-de-pesquisa é um exemplo de escola que opera com êxito nessa sociedade. Fundada em 1913, é uma das mais conceituadas escolas públicas estaduais do município, justamente pelos resultados que alcança nos índices que medem a qualidade do ensino. Apesar de manter ainda muitos aspectos da escola disciplinar, foram apresentandas no decorrer das observações algumas reatualizações que condizem com a sociedade de controle.

Durante a pesquisa, mantive mais contato com um dos assessores que era responsável pelas demandas do Ensino Médio Inovador e somente com alguns professores da turma do $3^{\circ}$ ano "1", onde fui trocando conversas, curiosidades, dúvidas sobre a organização da escola e sobre a turma pesquisada. Nessas conversas e nas observações que se deram o que se destacava era uma postura séria e engajada desses profissionais, na qual a preocupação sempre se pautava com os resultados do ENEM e as práticas pedagógicas desenvolvidas em sala configuravam-se quase um treinamento para o vestibular, seguia-se o fluxo da linha representativa. Entretanto, a maioria dos professores apresentavam-se bem qualificados e nas aulas observadas era possível perceber o domínio do conteúdo ensinado.

Por mais que os professores fossem abertos às discussões e sugestões dos protagonistas ${ }^{15}$, percebeu-se o estabelecimento de uma relação de distanciamento entre professor e aluno. Alguns professores impunham uma postura daquele que detém o saber e os estudantes assumem a postura daquele que recebe, o que conduz e o que é conduzido. Foi possível presenciar falas como: "eu ainda sou a professora dessa sala"; "mais respeito com quem está aqui na frente"; "vocês precisam estudar muito para questionar minha prática" "16, demonstrando a manutenção de uma escola na qual cada um possui seu papel determinado dentro do sistema de ensino, atuando no seu lugar de forma a respeitar as leis que regem suas atuações, evidenciando a manutenção de uma hierarquia nas relações de poder. Caruso e Dussel (2003, p. 37, grifo do original) explicam que "uma vez que a situação de ensino implica uma complexa situação de poder, consideremos que o ensino, como 'condução' da sala de aula, pode ser analisado em relação à condução das sociedades". Essa relação era ainda mais forte entre estudantes e o diretor, que nunca aparecia para conversar diretamente com os estudantes a não ser em homenagens cívicas, eventos específicos ou reuniões previamente agendadas. Recados eram passados pelas caixas de som instaladas nas salas. Observava-se uma direção distante, que nutria uma figura intangível.

Além dessas relações interpessoais, a escola fisicamente está estruturada nas bases da escola moderna: estrutura quadricular, janelas altas que não permitem ver o exterior da instituição, carteiras enfileiradas, sinal fragmentando o tempo e o saber, atividades cívicas de marcha e canto do hino nacional, uso do uniforme obrigatório, salas trancadas e só usadas com a autorização e acompanhamento do professor, enfim, o que se via na escola do século XVII ainda é possível se ver hoje na escola do século XXI, pois como escreve Passetti (2003), vivemos uma situação em que a sociedade disciplinar ainda não foi superada, mas a sociedade de controle prospera. Esta estrutura observada na escola, Foucault (1999) vai chamar de tecnologia disciplinar do trabalho, que permite o controle e o reconhecimento de todos dentro do espaço.

\footnotetext{
15 Entende-se que a palavra "protagonista" está na ordem do discurso da sociedade neoliberal. Por meio dessa palavra dá-se aos sujeitos uma suposta autonomia, colocando-os como responsáveis sobre suas próprias vidas. Entretanto, para esta pesquisa a palavra "protagonista" é atribuída aos sujeitos pesquisados devido ao trabalho feito com o uso das oficinas cinematográficas, cabendo a eles o papel principal de todo esse processo vivenciado. Uma tentativa de operar por outros fluxos.

${ }^{16} \mathrm{Na}$ escola pesquisada há em funcionamento somente duas turmas de EMI, uma do $3^{\circ}$ ano, com oito alunos e uma do $2^{\circ}$ ano, com seis alunos. As demais turmas do Ensino Médio fazem parte do ensino regular.
} 
O espaço disciplinar tende a se dividir em tantas parcelas quando corpos ou elementos há a repartir. É preciso anular os efeitos das repartições indecisas, o desaparecimento descontrolado dos indivíduos, sua circulação difusa, sua coagulação inutilizável e perigosa; tática de antideserção, de antivadiagem, de antiaglomeração. Importa estabelecer as presenças e as ausências, saber onde e como encontrar os indivíduos, instaurar as comunicações uteis, interromper as outras, poder a cada instante vigiar o comportamento de cada um, apreciálo, sancioná-lo, medir as qualidades ou os méritos. Procedimento, portanto, para conhecer, dominar e utilizar. (FOUCAULT, 2010, p. 138)

O primeiro prédio da instituição foi instalado na Praça Victor Konder, hoje sede da atual Prefeitura Municipal de Blumenau. A partir de 16 de novembro de 1968, as instalações físicas foram transferidas para uma rua situada numa bifurcação bem no Centro da cidade. Por estar estrategicamente localizada no centro, acaba por atender diversos bairros, com uma população bem diversificada em etnia, classe social, situação cultural, religiosa e etária. Conta com um total de aproximadamente 1.263 alunos, conforme estimativa de 2015, 79 funcionários, dentre eles 28 professores efetivos, 39 professores Admitidos em Caráter Temporário (ACTs), um diretor e três assessores.

A partir do ano de 2009, a Educação Infantil, pré-escolar, passou a ser administrada pela Prefeitura Municipal de Blumenau, utilizando-se apenas do espaço físico da escola-campo. Em 2010 foi implantado o Programa de Ensino Médio Inovador, instituído pela Portaria nº. 971, de 09/10/2009, no contra turno escolar do período diurno, visando desenvolver ações voltadas à melhoria do Ensino Médio, à superação das desigualdades de oportunidades educacionais, à universalização de acesso e permanência dos adolescentes (15 a 17 anos) no Ensino Médio e à oferta de aprendizagem significativa a todos, articulado a um modelo de ensino com forte enfoque no empreendedorismo, ensino de inglês e conhecimentos de informática e cursos técnicos (PPP, 2015, p. 11).

Em conversa com o assessor de direção, nos primeiros encontros que se deram sobre a possibilidade de realização da pesquisa na referida escola, foi-me informado que quando a escola implantou o Programa Ensino Médio Inovador contava com turmas cheias e a procura era alta. Entretanto, no ano de $2016^{17}$, possuía somente 14 alunos integrados, 8 no terceiro ano e 6 no segundo ano do Ensino Médio. Neste mesmo ano não foi cogitada a abertura de uma nova turma por falta de demanda, tanto de alunos quanto de profissionais especializados para trabalhar nas áreas artísticas (música e teatro) que fariam parte da grade curricular. Outro entrave na continuidade do programa é que muitos alunos foram desistindo no decorrer do ano por optarem por empregos remunerados em período comercial.

Durante as observações foram presenciados vários dilemas relacionados com o fechamento ou não das turmas existentes. No $2^{\circ}$ ano do EMI, dois estudantes queriam desistir do programa, pois argumentavam estar sendo prejudicados por uma professora e corriam o risco de reprovação. Contudo, a desistência desses dois estudantes resultaria no fechamento da turma, pois seria inviável a manutenção de uma turma somente com quatro estudantes. A questão maior que se instalava era que isso implicaria diretamente na contratação e remuneração de professores que perderiam suas aulas.

$\mathrm{Na}$ turma em que eu estava observando um caso parecido também repercutiu. Uma das meninas da turma não estava mais se sentido "à vontade" naquele grupo. Queixava-se frequentemente que era todo momento excluída das discussões e decisões, e que se perdia muito tempo com ladainhas e superficialidades naquela sala. Com a intervenção da mãe, fora solicitado

\footnotetext{
${ }^{17}$ Data de realização da produção dos dados.
} 
então, a troca da turma para uma regular. Entretanto, o problema foi se arrastando durante vários dias na tentativa de convencê-la que o EMI tinha muito mais qualidade de ensino no sentido de proporcionar maior atenção. Sem sucesso de convencimento, a aluna trocou de turma.

O Ensino Médio Inovador é uma política de currículo que integra as ações do Plano de Desenvolvimento da Educação (PDE), que foi instituída pelo Ministério da Educação do Governo Federal no ano de 2009, pela portaria No 971. Conforme Art. $1^{\circ}$ (BRASIL, 2009), o programa tem o objetivo de apoiar e fortalecer o desenvolvimento de propostas curriculares inovadoras nas escolas de ensino médio não profissional. $O$ programa deve dar ênfase aos projetos pedagógicos que promovam a educação científica e humanística, a valorização da leitura, da cultura, o aprimoramento da relação teoria e prática, da utilização de novas tecnologias e o desenvolvimento de metodologias criativas e emancipadoras (BRASIL, 2009, Art. $2^{\circ}$ ). O programa estabelece alguns regulamentos, tais quais:

Carga horária mínima de 3.000 (três mil horas), entendendo-se por 2.400 horas obrigatórias, acrescidas de 600 horas a serem implantadas de forma gradativa;

Foco na leitura como elemento de interpretação e de ampliação da visão de mundo, basilar para todas as áreas do conhecimento;

Atividades teórico/práticas apoiadas em laboratórios de ciências, matemática e outros que potencializem aprendizagens nas diferentes áreas do conhecimento;

Fomento às atividades de produção artística que promovam a ampliação do universo cultural do estudante;

Fomento as atividades esportivas e corporais que promovam o desenvolvimento dos estudantes;

Fomento às atividades que envolvam comunicação e uso de mídias e cultura digital, em todas as áreas do conhecimento;

Estímulo à atividade docente em dedicação integral à escola, com tempo efetivo para atividades de planejamento pedagógico, individuais e coletivas;

Incorporação das ações ao Projeto Político-Pedagógico implementado com participação efetiva da Comunidade Escolar;

As escolas participantes deverão promover a participação dos alunos no Exame Nacional do Ensino Médio - ENEM (BRASIL, 2014, p. 5).

Essas orientações estabelecem a permanência do estudante por um maior período de tempo na escola. Na instituição pesquisada os estudantes do EMI têm aulas de segunda à sexta-feira das $7 \mathrm{~h} 30 \mathrm{~min}$ às $11 \mathrm{~h} 30 \mathrm{~min}$ no período matutino e no período vespertino de terças às quintas-feiras das $13 \mathrm{~h} 30 \mathrm{~min}$ às $16 \mathrm{~h} 45 \mathrm{~min}$. Nas segundas e sextas-feiras à tarde, os líderes das turmas se encontram com os professores para realizar o planejamento pedagógico coletivo e elaborar projetos que seriam desenvolvidos no decorrer do ano articulado às temáticas do ENEM $^{18}$.

Nos dias de aula integral, os estudantes passam o período do almoço na escola. Têm um tempo para realizar suas refeições e depois podem usufruir de alguns espaços que ficam disponíveis, tais quais: auditório, biblioteca, laboratório de química, ginásio, para colocar suas atividades em dia, fazer tarefas, realizar os trabalhos solicitados pelos professores. Todavia, nos dias observados, os estudantes ficavam em suas próprias salas de aula, descansando nos colchonetes, assistindo a algum filme no auditório, navegando na internet de seus celulares ou jogando em algum aplicativo. Além de aproveitar esses momentos para descansar, também, descontraíam-se realizando alguma atividade interativa e colocando os assuntos em dia. Passetti (2003, p. 81), discorre que na sociedade de controle as pessoas recorrem às mídias para saber "o que é a realidade, verdade, divertimento e para participar do mundo". Não basta ter somente

\footnotetext{
${ }^{18}$ Esses encontros não foram acompanhados. Trago somente a existência desse período no PPP (2015) e seu objetivo, mas não tenho competência para dizer se eles eram realmente efetivados e de que forma aconteciam.
} 
um tempo e um espaço de descanso, é preciso distrações e conexões, "cada um se distrai, relaxa, e se educa para a mente se ocupar com produtividade virtual", porque o que interessa é uma mente ocupada e produtiva, mesmo nos períodos de descanso.

Outro aspecto a ser levantado, que se articula a esses momentos são os que refletem as seguintes falas: "eu queria estar em casa dormindo"; "poderia ter só artes e educação física à tarde"; "estamos sempre cansadas depois do almoço"; " a gente produz tão pouco à tarde"; "quando estou aqui queria estar em casa, quando estou em casa queria estar aqui". Tais falas mostram que os estudantes não querem atividades que exijam esforço intelectual no período vespertino. Demonstram exaustão e cansaço com o excesso de atividades e reconhecem que produzem mais pela manhã. A sociedade de controle ao investir em ocupar, vai produzindo um corpo que se controla, se conhece, se vigia para a produtividade. Eles sabem em que período são mais produtivos. Também, o fato de "produzir tão pouco à tarde", denuncia uma improdutividade e uma insatisfação observada na vivência em que as falas foram ditas. Parece que os estudantes, mesmo queixando-se das ocupações, lutam contra o cansaço, pois para esta sociedade é preciso estar produzindo sempre, continuamente, é preciso estar no fluxo, mantendo a mente sempre ativa. Não há espaço para ócio e quando há uma possibilidade para este espaço, ele é ocupado pelos meios midiáticos, como vimos acima.

A sociedade disciplinar foi cedendo a vez a uma sociedade de controle, baseada na produtividade do corpo, não mais ancorada na mecânica e numa disciplina em espaços, mas fazendo conhecer uma nova saúde do corpo. Agora o que interessa é a mente e esta deve ser tratada de maneira diferenciada. Ela deve ser ocupada de múltiplas atividades que possam vir a ser potencializadas, em um tempo de produtividade virtual individualmente, na qual o corpo como um todo deixa de ter importância. Agora são as partes que desempenham com habilidade o que antes se exigia do todo (PASSETTI, 2003, p. 81).

A sociedade de controle não produz só uma cultura de gestão e vigilância de si voltada para a produtividade, mas também, produz um corpo capaz de suportar as exigências dessa sociedade, um corpo que suporta esse ritmo acelerado de produção e que por mais fadigado continua se mantendo no fluxo. Ao afirmar que "quando se está em casa queria se estar na escola", evidencia-se uma vontade de estar naquele espaço independente do excesso de atividades e afazeres. O que leva o estudante a querer estar lá, talvez, seja o fato de poder estar na presença de amigos. Há queixa da ocupação, mas ao mesmo tempo, não se foge dela. $\mathrm{O}$ corpo disciplinado por outras modulações.

Talvez, o fato de o EMI possuir alguns privilégios quanto ao uso da internet durante o horário do almoço, supre esse cansaço e descontentamento, produzindo um sentimento de apaziguamento e conforto por meio da distração e da atuação. Passetti (2003, p. 81) afirma que estar conectado "constrói a imagem de si como cidadão midiático, participante de quaisquer decisões, sentindo-se livre para responder ao que lhe é solicitado e inserindo-se numa discursividade que sublima as sensações de liberdade". Na sociedade de controle é importante participar, atuar. Só tem reconhecimento aquele que participa, que produz, que opina, que se mostra, pois, "dizer não pode representar o risco de ser pinçado para fora; é preciso estar dentro, no vídeo, na tela: disseminando-se a paranoia, confirmando-se as solidões, as trapaças, os pulos do gato" (PASSETTI, 2003, p. 250, grifo do original). É preciso dizer quem se é e o que se pensa, mesmo que "não há aspiração sequer para a reflexão, apenas o convite para participar e se filiar a uma corrente de opiniões" (PASSETTI, 2003, p. 272). As redes sociais, talvez, sejam 
as vitrines desta participação ou o novo panóptico ${ }^{19}$, onde um vigia os outros, todos se vigiam, de forma a buscar "anular as resistências pelos dispositivos de integração e consenso" (PASSETTI, 2003, p. 271, grifo do original). Eu me mostro, por conseguinte, me identifico, me localizo, possibilito o controle sobre mim, por meio de uma confissão, um exame. Vive-se um tempo de regulação do self, onde o conhecimento que é produzido e disseminado no âmbito escolar vai determinando/constituindo/regulando nossa maneira de ser, agir e pensar no mundo.

Grande parte da vida moderna é preparada por sistemas de conhecimento especializados que disciplinam a maneira como as pessoas participam e agem. De modo geral, o conhecimento especializado modela o 'nosso' pensamento e a 'nossa' ação sobre as calorias da nossa dieta, contribuindo para a nossa saúde pessoal; sobre a poluição no nosso ambiente, que afeta a nossa vida; sobre o nosso corpo e a nossa mente, como possuidores de estágios de desenvolvimento, personalidade e processos de auto-realização, e sobre nossas crianças, como dotadas de inteligência, com um crescimento e uma infância normais. Esses pensamentos assumidos como naturais não são naturais; são construídos a partir de sistemas de conhecimento especializados. O poder desse conhecimento especializado está no fato de não ser apenas conhecimento. As ideias funcionam para modelar a maneira como participamos como indivíduos ativos e responsáveis. (POPKEWITZ, 2001, p. 13).

O regulamento do EMI trazido anteriormente, também estabelece projetos que fomentem atividades esportivas e artísticas, assim sendo, na grade curricular da escola, além das aulas de Ed. Física e de Artes, os estudantes ainda tinham um projeto paralelo de vôlei e possuíam aulas de teatro. Dentre tantas disciplinas que seriam possíveis na composição desse currículo, estas aparecem com a função de "cuidar do corpo trazendo-lhe saúde, fazer produzir e conhecer culturas" (PASSETTI, 2003, p. 58), afinal, "zelar pela saúde do corpo produtivo é também administrar as doenças da economia" (PASSETTI, 2003, p. 241). É por meio do esporte que se prolonga a saúde do corpo, "equacionando-se doenças abreviadoras de impacto" (PASSETTI, 2003, 254). Preza-se pela saúde e jovialidade do corpo, recomendando diversos cuidados, práticas, acompanhamentos que recaem a outras áreas do conhecimento, como a medicina, a psicologia, a nutrição, de forma a combater a precipitação da morte e instaurar um padrão estético do que é ser saudável. A instauração desse padrão torna o corpo um investimento, induzindo-o a uma busca incessante e contínua pela manutenção da vida, pois

Estas amostras de interceptações exemplares atingem o corpo em sua produtividade intelectual, fundada na velocidade, acúmulo de conhecimento, tensão, táticas e performances diplomáticas. A sociedade de controle não precisa de força mecânica, mas de força eletrônica, intelectual, em fluxo contínuo (PASSETTI, 2003, p. 255, grifo do original).

As aulas de artes e de teatro vêm desta maneira contribuir para o desenvolvimento desta força intelectual, uma vez que, "o corpo como potencial de vida também repercute em evidências artísticas, criando condições para a emergência de autorias que atuam modificandoo circunstancialmente, para expô-lo nos seus fragmentos" (PASSETTI, 2003, p. 255).

Ainda sobre comunicação e uso de mídias e cultura digitais, o regulamento " $F$ " reforça e convoca todos a estarem conectados. Os protagonistas faziam uso do laboratório de informática

\footnotetext{
${ }^{19}$ Estrutura de vigilância prisional concebida pelo filósofo e jurista inglês Jeremy Benthan. Abordado no livro Vigiar e Punir. Cf. FOUCAULT, 2010.
} 
por meio de diversas disciplinas na realização de projetos de pesquisa. Este, também, era um espaço que ficava disponível nos horários de almoço. Entretanto, pela precariedade dos equipamentos de computação e internet, quase não se fazia uso deste espaço. Os protagonistas preferiam utilizar seus próprios aparelhos celulares, que eram liberados pela instituição escolar. Segundo o PPP (2015, p. 8) da escola, desde 2014 há um projeto de incentivo ao uso do celular como ferramenta pedagógica que contribui na aprendizagem.

Durante as perambulações que fazia pela escola percebia que quase todos os estudantes andavam com seus fones de ouvido pendurados estrategicamente no uniforme escolar. Na turma do $3^{\text {o } ~ " 1 " ~ t o d o s ~ o s ~ e s t u d a n t e s ~ u t i l i z a v a m ~ s e u s ~ c e l u l a r e s ~ d u r a n t e ~ a s ~ a u l a s, ~ o r a ~ p a r a ~ f a z e r ~}$ pesquisas, ora para passar o tempo, escutando música, jogando, conversando no Whatsapp, atualizando o Facebook e as informações. Fazia-se desnecessário chamar a atenção quanto ao uso indevido do aparelho, pois, aparentemente, todos sabiam o momento "apropriado" de utilização. As sociedades transitam, mas as marcas do disciplinamento ainda são visíveis e sensíveis. Em provas ou em momentos de explicação dos conteúdos, o uso do aparelho era proibido e os protagonistas automaticamente desligavam seus celulares sem que ninguém precisasse os intimar. Veiga-Neto (2009) vai argumentar que o poder disciplinar surge como uma invenção extremamente produtiva e econômica, que com um mínimo de investimento, sofrimento e alarde, obtêm-se resultados maximizados, duradouros e microfísicos e que quando exercido de maneira eficiente e cuidadosa não raro passa despercebido.

Em conversa com os estudantes, em uma das observações realizadas durante a aula de Educação Física, uma delas relatou-me que "a escola já não pode mais proibir o uso do celular, é preciso compreender que isto já faz parte de nossas vidas". Os problemas com o uso do celular na instituição pesquisada, aparentemente ou temporariamente, foram solucionados. A liberdade sempre vem acompanhada de certas restrições, pois, a tecnologia como sendo aquele local que escapa da materialidade e que é atravessada por fluxos que permitem sabotagens ou fugas, precisa ser legislada (PASSETTI, 2003). Nesse espaço, o uso do aparelho celular já se normalizou, é a sociedade de controle operando por fluxos que vão substituindo a estrutura panóptica de controle e vigilância por redes eletrônicas de comunicação que atuam no agenciamento dos desejos ${ }^{20}$ exigindo sempre mais participação. Ficamos transparentes, alega Passetti (2003, p. 129). O autor reitera ainda, que,

[o] investimento passou a ser no corpo são, nos fluxos inteligentes [...] e conectados globalmente por redes eletrônicas de comunicação. O panóptico tão discutido a partir dos estudos de Foucault sobre as sociedades disciplinares deixou de ser o dispositivo disciplinar preponderante. Agora, não estamos mais em um mundo onde um olha para muitos, mas no seu reverso, no qual muitos olham para o eletrônico, traduzido numa midiosfera governada por sinopses, em que prevalece a televisão, as sondagens, os programas de computação e a Internet (PASSETTI, 2003, p. 13, grifo do original).

Outro projeto de relevância, articulado ao Programa Inovador, é o chamado Empreendedorismo. Projeto este que tem por objetivo:

\footnotetext{
${ }^{20} \mathrm{O}$ desejo consiste no movimento de afetos gerados no encontro dos corpos. Os agenciamentos são forças de natureza heterogêneas que investem no desejo para produzir algo, pois, "o desejo é criação de mundo" como assinala Rolnik (2014, p. 56) e diz mais, "não existe sociedade que não seja feita de investimentos de desejo nesta ou naquela direção, com esta ou aquela estratégia e, reciprocamente, não existem investimentos de desejo que não sejam os próprios movimentos de atualização de um certo tipo de prática e discurso, ou seja atualização de um certo tipo de sociedade" (ROLNIK, 2014, p. 56). "O desejo é sempre agenciado, ele é o que o agenciamento determina que ele seja” (DELEUZE; GUATTARI, 2012, p. 122).
} 
1. Criar práticas de interações entre diversos atores: empresas, instituições de pesquisa, universidades, agências de planejamento ou de fomento à inovação;

2. Desenvolver o senso crítico, a percepção e identificação de estratégias inovadoras, para a aplicação dos conhecimentos nos campos econômicos, político e/ou social;

3. Estreitar as relações entre família, escola e comunidade;

4. Proporcionar debates e reflexões sobre as atitudes de um empreendedor (PPP, 2015, p. 42).

Criar, planejar, desenvolver, criticar, estrategizar, refletir, inovar. Inovar, nome dado ao próprio currículo: Ensino Médio Inovador. Palavra que do latim innovare, suscita renovação, mudança. Nada permanece, tudo se encontra em constante transmutação. Quando digitada no provedor de pesquisa a palavra inovar aparece vinculada em artigos e reportagens das áreas de marketing, empreendedorismo empresarial, comércio, relações públicas, publicidade e propaganda. Áreas estas ligadas a um sistema econômico que busca por sujeitos capazes de fazer essa economia proliferar, gerando sempre mais capital e sujeitos consumidores.

A fábrica cedeu lugar à empresa, e a escola passou a ser empresa também. Todas essas estratégias de programas e projetos que compõe o currículo do Ensino Médio Inovador esporte, teatro, aulas de informática, projetos de pesquisa, trabalhos em grupo, incentivo à aprendizagem de línguas e ao empreendedorismo, ocupação, vieram para gerir mentes criativas, participativas, inteligentes e saudáveis, afinal, nessa sociedade, "tudo depende do cérebro" (PASSETTI, 2003, p. 260, grifo do original) e não da força braçal. Diferente da sociedade disciplinar, o que está em jogo é reger um corpo vivo, produtivo e são, conforme salienta Passetti (2002) e enfatizo: inteligente.

Se na sociedade disciplinar se investia no corpo enquanto força produtiva, esta sociedade investe na inteligência.

As partes inteligentes do corpo é que mandam; elas fazem existir, elas definem as partes que privilegiam, uma sociedade em pedaços, do sexo em pedaços, da fragmentação. Uma sociedade que dispensa a especialização e que necessita cada vez mais de trabalhadores polivalentes (PASSETTI, 2002, p. 100).

Elas definem as partes que privilegiam: a criatividade, a autonomia, a liderança, a sociabilidade, posturas que tais disciplinas mencionadas acima têm como objetivo desenvolver, não mais um especialista, mas um trabalhador polivalente. Tão polivalentes que, são os estudantes do EMI os que mais produzem pesquisa na escola, pois estão a todo o momento desenvolvendo e articulando projetos interdisciplinares com saídas de campo, envolvendo a comunidade escolar e outras turmas de forma a expor/apresentar esses projetos e prover conscientização com temáticas transversais. A participação é a exigência do momento, "a participação estimulada, reforçada e imperativa faz crer e faz produzir um indivíduo que precisa mostrar que está vivo" (PASSETTI, 2002). Em falas como: "o que seria dessa escola se não fosse o EMI"; "tudo sobra pra gente"; "vamos lá, encarar mais um projeto, no fim, alguma coisa sempre se aprende"; "eu não sei o que eu estaria fazendo em casa, se eu não estivesse no Inovador"; ao mesmo tempo em que evidenciam marcas de superioridade, meritocracia e performatividade - a escola produz desigualdades, classifica e acentua/naturaliza as diferenças -, estas falas também evidenciam uma constante ocupação por via da participação. Mantém-se o estudante o tempo todo ocupado com a justificativa de que para serem os melhores é preciso participar de todas as propostas de ensino-aprendizagem. Segundo Passetti (2003) o que 
interessa para esta sociedade é a mente e esta deve ser tratada de forma diferenciada, acusando uma ocupação constante:

Ela deve ser ocupada com múltiplas atividades que possam vir a ser potencializadas, em um tempo de produtividade virtual individualmente, na qual o corpo como um todo deixa de ter importância. Agora são as partes que desempenham com habilidade o que antes se exigia do todo. [...] Em tudo deve haver mais trabalho e mente ocupada (PASSETTI, 2003, p. 81, grifo meu).

A sociedade de controle opera no agenciamento do desejo, quando se ouve: "eu não sei o que eu estaria fazendo em casa", vê-se o dispositivo de captura produzir uma subjetividade escolarizada, que subtrai as potências do corpo, anulando suas singularidades e seu protagonismo em face à sociedade e a vida. São os dispositivos de poder atuando, produzindo, agenciando. $\mathrm{O}$ que se pretende não é alguém que fique em casa, improdutivo, ocioso, mas alguém que não consiga ficar fora dos fluxos que atravessam esta sociedade de ocupação constante. Em um dos momentos em que aconteceram as oficinas, uma das estudantes levantou a questão de que "eu não gosto de me sentir inútil" e outra complementou, "eu não suporto ficar em casa nas férias, porque me sinto inútil”. Para esta sociedade é preciso estar produzindo sempre, participando muito e se afirmando constantemente. É o corpo vivo que "permanece útil e dócil" (PASSETTI, 2003, p. 248). Um corpo que não gosta, que não suporta a falta de ocupação, um corpo que sofre as afecções de micropoderes operando com êxito na produção de novo reitero - de necessidades e sujeitos necessitados (CERVI, 2013, p. 46). Para este tempo é preciso, como diz uma das protagonistas: "fazer alguma coisa, qualquer coisa, só não ficar parado num mesmo lugar”. Manter-se na escola é a regra do jogo, formação contínua, ocupação sempre, mais e sempre mais escolarização. Fluxos que não param de produzir (CERVI, 2013).

\section{Algumas saídas do mapa...}

As coisas mudam no devagar depressa dos tempos.

[Guimarães Rosa]

Estes mapas do espaço-tempo da instituição escolar que foram traçados e apresentados permitem-nos acompanhar a transição da sociedade disciplinar à sociedade de controle e as modulações da escola nessa transição. Permitem-nos também perceber que tanto na sociedade disciplinar quanto na sociedade de controle, as forças sempre recaem sobre o corpo na tentativa de potencializá-lo, torná-lo produtivo para o sistema político-econômico atuante. A questão é sempre o corpo e o que ele pode. Muda-se as estratégias, as ferramentas, os dispositivos, mas o que se objetiva é sempre um corpo ativo e produtivo.

A cartografia possibilitou vivenciar uma política de currículo operando na escola que vem ao encontro do que Lopes (2006) afirma sobre sua organização: um currículo com base nos objetivos comportamentais, a estruturação curricular com base nas competências e o planejamento do currículo com base na divisão de tarefas. Esta organização pode ser vista no estabelecimento de projetos voltados a atividades científicas, matemáticas, artísticas, esportivas, culturais, fomentando e estimulando a participação, comunicação, ao uso das mídias e tecnologias digitais, integrando atividades coletivas e enfatizando o caráter inovador.

Este currículo que determina como carga horária mínima obrigatória três mil horas de estudos e dedicação anuais pode possibilitar a abertura para se pensar e criar outras coisas dentro do espaço escolar. Entrementes, o que mais se pode verificar nesse tempo e espaço pesquisado é um currículo que alveja despotencializar o corpo criativo e colocá-lo num 
fluxo de uma sociedade que busca um corpo cada vez mais produtivo (PASSETTI, 2003) e performático (BALL, 2010). Um currículo que além, de manter o corpo constantemente regulado, o mantém cada vez mais ocupado. A sociedade de controle a o investir em ocupar vai produzindo um corpo que se controla, se conhece, se vigia para a produtividade e o auto desempenho dentro de uma cultura de gestão e vigilância de si (CERVI, 2013). O que interessa para esse tempo é que cada um se constitua conforme o que Sennett (2006) vai chamar de empresa de si, sustentando um corpo capaz de suportar as exigências dessa sociedade, um corpo que se submete a um ritmo acelerado de produção e que por mais fadigado continua se mantendo no fluxo... Um corpo (con)formado a uma lógica neoliberalista, um corpo normalizado.

A política de currículo do Ensino Médio Inovador opera na escola como um dispositivo de poder-saber na constituição do sujeito escolar e está alinhada com a sociedade de controle. Ela engendra mecanismos de regulação dos docentes e dos discentes, de forma a garantir a eficiência e a eficácia dos sistemas de ensino, que ao contrário dos discursos do governo, não estão em crise. Ela opera com sucesso ao ampliar o tempo de escolarização, ao ampliar os espaços, ao incluir todos, ao permitir a participação, ao reatualizar o currículo e a legislação. Ela produz o que dela se espera, como afirma Cervi (2013).

Diante disso, cabe a nós questionarmo-nos e buscarmos no mapa outros caminhos que nos levem a outras saídas, fugas, possibilidades para a criação de novos traços ou de rabiscos que desobedeçam a lógica arborificada, mas que encontrem nas linhas do rizoma uma possibilidade para outras estéticas do corpo e da existência. Pensar numa educação mais subtraída da representação, da explicação, da ocupação, da empresa em nós e potencializar uma educação mais "a(r)tiva"... Viva, artística, ativa. Uma educação para a criação, para a emancipação, para a experimentação. Seguir afetado pela provocação de Anitelli (2008): "Não acomodar com o que incomoda" e encontrar na escola um espaço onde é possível brotar como erva daninha, sempre fluida, dinâmica e resistente. Pois, além da docilidade, utilidade, participação e corpos performáticos, na escola pulsam energias e afetados também vamos nos encontrando e usando as energias para práticas inventivas... Na escola também inventamos.

\section{Referências}

ANITELLI, F. Criado-mudo. Segundo ato (c/ O Teatro Mágico). Independente, CD, 2008.

BALL, S. J. Profissionalismo, Gerencialismo. Performatividades e fabricações na economia educacional: rumo a uma sociedade performativa. Educação e realidade, v. 35, n. 2, 2010, p. 37-55.

BRASIL. Secretaria de Educação Básica. Diretoria de Currículos e Educação Integral Coordenação geral do Ensino Médio, 2014. Programa Ensino Médio Inovador. Documento orientador, Brasília, 2014.

BRASIL. Diário oficial da União. n. 195, terça-feira, 13 de outubro de 2009.

CARUSO, M.; DUSSEL, I. A invenção da sala de aula: uma genealogia das formas de ensinar. Tradução de Cristina Antunes. São Paulo: Moderna, 2003.

CARVALHO, A. F. de; GALLO, S. Do sedentarismo ao nomadismo: intervenções para pensar e agir de outros modos na educação. ETD - Educ. Tem. Dig., Campinas, v. 12, n. 1, p. 280-302, jul./dez. 2010 
CERVI, G. M. Política de Gestão Escolar na Sociedade de Controle. Rio de Janeiro: Editora Achiamé, 2013.

CORRÊA, M. O que pode um corpo na escola?: Uma cartografia das potencialidades do corpo em espaço de escolarização. 2017. 121 f. Dissertação (Mestrado em Educação). Universidade Regional de Blumenau, Blumenau, 2017.

DELEUZE, G. Conversações (1972-1990). 3. ed. Tradução de Peter Pál Pelbart. São Paulo: Editora 34, 2013.

DELEUZE, G. Lógica do sentido. Trad. Luiz Roberto Salinas Fortes. São Paulo: Perspectiva, 2006.

DELEUZE, G. Diferença e repetição. Tradução de Luiz Orlandi e Roberto Machado. Lisboa: Relógio d'Água, 2000.

DELEUZE, G.; GUATTARI, F. Mil platôs: capitalismo e esquizofrenia 2, vol. 3. 2. ed. Tradução de Aurélio Guerra Neto, Ana Lúcia de Oliveira, Lucia Claudia Leão e Suely Rolnik. São Paulo: Editora 34, 2012.

DELEUZE, G.; GUATTARI, F. Mil Platôs: capitalismo e esquizofrenia 2, vol. 1. 2. ed. Tradução de Ana Lucia de Oliveira, Aurélio Guerra Neto e Celia Pinto Costa. São Paulo: Editora 34, 2011.

FOUCAULT, M. Vigiar e Punir: Nascimento da Prisão. 38. ed. Tradução de Raquel Ramalhete. Petrópolis, RJ: Vozes, 2010.

FOUCAULT, M. Nascimento da biopolítica: Curso dado no Collège de France (1978-1979). Edição estabelecida por Michel Senellart sob a direção de François Ewald e Alessandro Fontana. Tradução: Eduardo Brandão. São Paulo: Martins Fontes, 2008.

FOUCAULT, M. Em Defesa da Sociedade: Curso no Collège de France (1975-1976). São Paulo: Martins Fontes, 1999.

FREUD, S. O inquietante. In.: FREUD, S. Obras Completas (1917-1920). Vol. 14. Tradução Paulo César de Souza. São Paulo: Companhia das Letras, 1919.

LOPES, A. C. Discursos nas políticas de currículo. Currículo sem fronteiras, v. 6, n. 2, p. 33$52,2006$.

ORWELL, G. 1984. Tradução Alexandre Hubner, Heloisa Jahn. São Paulo: Companhia das Letras, 2009.

PASSETTI, E. Anarquismos e sociedade de controle. São Paulo: Cortez, 2003.

PASSETTI, E. Ecopolítica: o que pode um corpo? In.: In.: LINS, D.; GADELHA, S. (Org.). Nietzsche e Deleuze: Que pode o corpo. Rio de Janeiro: Relume Dumará; Fortaleza, CE: Secretaria da Cultura e do Desporto, 2002, p. 91-107. 
PASSOS, E.; KASTRUP, V.; ESCÓSSIA, L. (Org.). Pistas do método da cartografia: pesquisa-intervenção e produção de subjetividade. Porto Alegre: Sulina, 2009, p. 52-75.

POPKEWITZ, T. S. Lutando em defesa da alma: a política do ensino e a construção do professor. Tradução de Magda França Lopes. Porto Alegre: Artmed Editora Ltda., 2001.

PPP. Projeto Político Pedagógico. Governo de Estado de Santa Catarina. Secretaria de Estado da Educação. Gerência Regional de Educação. Blumenau, 2015.

RAMOS DO Ó, J. O governo de si mesmo: modernidades pedagógicas e encenações disciplinares do aluno liceal (último quartel do século XIX - meados do século XX). Editor: Educa, 2003, p. 764 (Coleção Educa-Ciências Sociais).

ROLNIK, S. Cartografia sentimental: transformações contemporâneas do desejo. 2. ed. Porto Alegre: Sulina; Editora da UFRGS, 2014.

SCHÖPKE, R. Por uma filosofia da diferença: Gilles Deleuze, o pensador nômade. 1. reimpr. Rio de Janeiro: Contraponto, 2012.

SKLIAR, C. Desobedecer a linguagem: educar. 1. ed. Belo Horizonte: Autêntica Editora, 2014.

SILVA, T. T. da. Documentos de identidade: uma introdução as teorias do currículo. 3. ed. 4. reimp. Belo Horizonte: Autêntica Editora, 2013.

SENNETT, R. A cultura do novo capitalismo. Tradução Clóvis Marques. Rio de Janeiro: Record, 2006.

VARELA, J.;ALVAREZ-URIA, F. A Maquinaria escolar. Teoria \& Educação. São Paulo, n. 6, p. 68-96, 1992.

VEIGA-NETO, A. Uma vila voltada para trás. In.: GALLO, S.; VEIGA-NETO, A. (Org.). Fundamentalismo \& Educação - A Vila. Belo Horizonte: Autêntica Editora, 2009, p. 67-106.

VETTER, C. I. O retrato da nudez eólica. 2. ed. Blumenau: Liquidificar Produtos Culturais, 2011. 